\title{
Research on interpersonal violence in schizophrenia: based on different victim types
}

\author{
Yong He, Yan Gu, Meiling Yu, Yan Li, Gangqin Li* and Zeqing Hu*
}

\begin{abstract}
Background: Schizophrenia is one of the most common severe mental disorders associated with an increased risk of violence. The present study compares the demographical, clinical, and criminological characteristics of the patients with schizophrenia who committed different types of violence to relatives, acquaintances, or strangers.

Method: Archives of the violent offenders with schizophrenia referred to forensic psychiatric assessments from January 2015 to December 2019 in the West China Forensic Medicine Assessment Center in China were analyzed. The demographic information, mental illness history, and criminological characteristics of the offenders were collected. The clinical symptoms, previous violent behaviors, and social deficits were also evaluated. One-way ANOVA, KruskalWallis test, Chi-square test, and logistic regression analysis were enrolled to do the statistical analysis.

Results: The study enrolled 332 cases: 165 cases (49.7\%) in the acquaintance victim group (AV), 96 cases (28.9\%) in the relative victim group (RV), and 71 cases (21.4\%) in the stranger victim group (SV). The multinomial logistic regression analysis revealed that older patients were less likely to attack relatives $(\mathrm{OR}=0.966,95 \% \mathrm{Cl}=0.944-0.990$; $p=0.005)$, and strangers, $(\mathrm{OR}=0.971,95 \% \mathrm{Cl}=0.944-0.998 ; p=0.034)$. Patients who lived with others were more inclined to attack relatives $(\mathrm{OR}=15.057,95 \% \mathrm{Cl}=3.508-64.628 ; p<0.001)$. Additionally, employed patients were more likely to attack strangers $(\mathrm{OR}=2.034,95 \% \mathrm{Cl}=1.036-3.994 ; p=0.039)$. The regression equation did not include $p s y-$ chiatric symptoms. For RV and AV victims, the risk of death was higher compared to that of SV victims $(O R=13.778$, $p<0.001 ; \mathrm{OR}=2.663, p=0.014)$.

Conclusion: In the interpersonal violence cases committed by schizophrenia patients, the victim type correlates with demographic characteristics of offenders such as living situation, age, and employment status, but not with the psychiatric symptoms. The majority of victims were acquaintances and relatives, and the relative victims having more severe injuries. In order to decrease interpersonal violence, especially violent crimes, more people, especially family members and neighbors, should be educated about symptoms of schizophrenia, the ways to communicate with the patients, and the methods for crisis management.
\end{abstract}

Keywords: Schizophrenia, Interpersonal violence, Victim relationship, Criminological characteristics, Clinical characteristics, Demographic characteristics

*Correspondence: gangqinli@scu.edu.cn; huzeqing@126.com Department of Forensic Psychiatry, West China School of Basic Medical Sciences and Forensic Medicine, Sichuan University, Sichuan 610041 Chengdu, China

\section{Introduction}

Schizophrenia is a severe mental disorder [1], which the public often related to violent behavior [2,3], and several studies have shown that schizophrenia increases the risk of violent behavior [4-7]. Previous studies have focused 
on the clinical and criminological characteristics of schizophrenia patients committing violent acts, most of whose control groups were healthy people or patients without violent behavior. Few studies have sought to compare the characteristics of schizophrenic patients who commit interpersonal violence with different victim types. The generation of interpersonal violence is an interactive process of the perpetrator and victim, relevant to the surrounding people and the environment. The course and the outcome of violent behavior from schizophrenia may vary depending on the type of victim, which may elicit different social impacts. Compared to clinical management of the mentally ill (eg. risk assessment, improved treatment), the relatively rare and unpredictable violence among psychiatric patients are more likely to raise public concerns and increase the stigma of the patients [8].

Cases of injury or murder among strangers in public places tend to raise public awareness and panic. Previous studies have also documented several forms of victimization. The investigation of homicide cases has shown that the mentally ill are less likely to attack strangers [9-13]. In contrast, families and friends of individuals with mental disorders face the most significant risk of harm [14]. Patients with severe mental disorders like schizophrenia commit half of the violent acts directly on family members $[15,16]$. A Japanese study showed that $34.8 \%$ of family members of schizophrenia patients had experienced physical violence from the patient [17]. According to a meta-analysis, at least $40 \%$ of relatives of mental disordered people were injured by the patients [18]. Schizophrenia has a stronger association with homicide than other diagnoses of mental disorders [19, 20]. Among patients with mental disorders who have murdered relatives, more than $50 \%$ were schizophrenia patients $[21,22]$. Concerning the injury severity, relatives of people with mental disorders had a higher probability of suffering severe or fatal violence [23, 24]. Psychiatric criminals have a higher propensity to commit crimes alone, in public, and against strangers than nonpsychiatric criminals [25].

The study of the risk factors related to offenders in different categories of victim is insufficient. How do demographic characteristics and clinical characteristics influence the type of victims of violence in people with schizophrenia? Moreover, what are the criminological characteristics of the offenders according to different types of victims? To answer these questions, we conducted a comparative study of forensic psychiatry assessed cases of schizophrenia suspected of violent crimes based on the categories of the victim hoping to provide a framework for identifying individuals at high risk of violent victimization and developing preventive measures.

\section{Study subjects}

We reviewed archival data of schizophrenia suspects assessed at the West China Forensic Medicine Assessment Center in Sichuan Province, China, from January 2015 to December 2019, with the inclusion criteria as following: (1) have interpersonal violence; (2) was diagnosed with schizophrenia according to the criteria of the Chinese Classification of Mental Disorders- $3^{\text {rd }}$ edition (CCMD-3), and no other comorbidities; (3) Completed case data. In this study the interpersonal violence was about physical violence against others' bodies. All the eligible cases were categorized into 3 groups according to different types of victims(relatives, acquaintances, or strangers as victims respectively).If there were multiple victims in one case, we grouped them based on the first victim. The ethics committee board of Sichuan University approved this study.

\section{Methods}

This retrospective study used a framework of forensic psychiatry sample, with the required law enforcement agencies providing the necessary information for the assessment, including demographic information, medical records, and the files of criminals. The data from their forensic psychiatric assessment and the files of criminals contain demographic, gender, ethnicity, year of birth, education level, marital status, place of residence, employment history, living situation, family history of mental illness, and drug abuse. We collected the data of criminological characteristics, the location of the interpersonal violence, the gender and relationship of the victims, the tools used, and the patients' criminal history. We applied the Brief Psychiatric Rating Scale to evaluate clinical characteristics and psychiatric symptoms, the Social Disability Screening Schedule (SDSS) to appraise the social function. We also collected the patient's past hospital visits and medication status. In the forensic psychiatric assessment center, two psychiatrists evaluated the patient's mental status according to the CCMD-3, which originated in the ninth edition of the International Classification of Diseases [26, 27], but now corresponds to the 10th edition of the International Classification of Diseases [28].

\section{Measurement The Brief Psychiatric Rating Scale (BPRS)}

The Brief Psychiatric Rating Scale (BPRS) [29] is one of the standard instruments commonly used in daily practice to evaluate the severity of schizophrenia-related symptoms, and the 18-item scale is widely used [30]. This scale includes five subscales as follows: Affect (anxiety, guilt, depression, somatic); Positive Symptoms 
(thought content, conceptual disorganization, hallucinatory behavior, grandiosity); Negative Symptoms (blunted affect, emotional withdrawal, motor retardation); Resistance (hostility, uncooperativeness, suspiciousness); and Activation (excitement, tension, mannerisms-posturing) [31].

\section{The Social Disability Screening Schedule(SDSS)}

The Social Disability Screening Schedule (SDSS) used in this study was a simplified Chinese version of the World Health Organization's Disability Assessment Schedule [32], which assesses ten different aspects of social function, and each item has a score ranging from 0 to 2 . The higher the score, the worse the social function outcome. Twelve areas epidemiological survey of mental disorders in China stipulated a total score of $\geq 2$ points, which indicates a functional social deficit [33].

\section{Statistical analysis}

All analyses were performed using IBM SPSS Statistics (version 20.0). The significance level was 0.05 (2-sided). Three independent groups were compared using a oneway analysis of variance (ANOVA) or the Kruskal-Wallis $\mathrm{H}$ test. The Chi-squared test was used to compare the categorical variables across the three groups. Bonferroni's correction for multiple comparisons was used for pairwise comparisons between groups. Multinomial logistic regression was used to analyze the risk factors for offenders targeting different type of victims.

\section{Results}

A total of 332 cases were included in the current study, while 165 cases (49.7\%) in the Acquaintances Victim group (AV), 96 cases $(28.9 \%)$ in the Relatives Victim group (RV), and 71 cases $(21.4 \%)$ in the Stranger Victim group (SV). The average age of the offenders was $40.16 \pm 12.04$ years old, $97.0 \%$ were Chinese Han population, and $81.0 \%$ were men. There were $79.2 \%$ of the offenders had a low level of education ( $\leq 9$ years), most of them lived in rural areas (73.2\%), and $23.5 \%$ of them never had a job before. There were $79.2 \%$ of the patients were unemployed at the time of the violence. Regarding marriage, only $36.4 \%$ were married, while the rest were unmarried, divorced, or widowed. In terms of the living situation, $79.2 \%$ lived with others and $20.8 \%$ lived alone. A total of $73.8 \%$ had sought treatment in a psychiatric facility before the violence occurred, and $55.1 \%$ were hospitalized. The majority of patients $(67.4 \%)$ had the disease for more than five years. Nearly four-fifths of the patients did not take medicine at the time of committing the violence. A family history of mental illness is present in $8.7 \%$ of cases. The percentage of patients with a criminal record was $9.3 \%$. Regarding substance use, $12.3 \%$ of offenders drank alcohol before committing the interpersonal violence, and none were drug users (Table 1).

For the types of interpersonal violence, 217 cases (65.4\%) were physical assault, and 115 cases $(34,6 \%)$ were murder. In terms of the location of the interpersonal violence, public places accounted for the highest proportion at $52.1 \%$, followed by co-residence $23.2 \%$, and victim residence (16.9\%); $83.7 \%$ of suspected offenders used tools, of which $48.2 \%$ brought tools to the criminal scene, and $51.8 \%$ used tools on-site. There were $84.6 \%$ offenders had repeated attack behavior. In $41.3 \%$ of the cases, the victims contain at least one woman, and in $35.8 \%$ of the cases, the victims encountered death problems (Table 1).

\section{Comparison of characteristics among groups Demographic characteristics}

Gender, ethnicity, education level, and employment history did not differ among the groups $(p>0.05)$. In addition, differences among the three groups were found based on demographic factors such as age, living situation, employment status, place of residence, and marital status. The age of the AV $(42.98 \pm 12.75$ years old) was significantly higher than that of the RV (37.07 \pm 11.36 years old) and the SV (37.79 \pm 9.56 years old) statistically $(p<0.001)$. By living situation, more patients lived with others in the RV (97.9\%) group than the AV $(72.1 \%)$ and SV $(70.4 \%)(p<0.001)$. Regarding the employment status, more patients in the SV group were in employment compared to those in the AV (17.0\%) and RV $(17.7 \%)(p=0.009)$. A marginal significant difference was found in place of residence categories $(p=0.056)$ and marital status $(p=0.050)$, that a higher percentage of schizophrenia offenders attacking acquaintances living in the rural area (78.8\%) compared to those in the RV (69.8\%) and SV (64.8\%). The proportion of married patients in the SV (28.2\%) was lower than that of the AV (34.5\%) and RV (45.8\%) $(p=0.050)$, (Table 2).

\section{Clinical characteristics}

In concern of the clinical characteristics, there were no statistically significant differences in terms of the history of psychiatric treatment, hospitalization, illness duration, treatment, and alcohol use when committing the index interpersonal violence, as well as family history of mental disorders $(p>0.05)$ (Table 2).

Regarding the social function, the median score of SDSS for offenders in RV was 8.00, in AV was 8.00, and in SV was 7.00, and the score distributions did not differ significantly among the three groups $(H=4.075$, $p=0.130$ ) (Table 3).

The BPRS indicated no significant differences in the affect and activation scores among groups $(p>0.05)$, however, it showed statistically significant differences in 
Table 1 Demographic, clinical and criminological characteristics of the study sample

\begin{tabular}{|c|c|}
\hline & $n(\%)$ \\
\hline \multicolumn{2}{|c|}{ Demographic characteristics } \\
\hline Age [Mean (SD)] & $40.16(12.04)$ \\
\hline \multicolumn{2}{|l|}{ Sex } \\
\hline Male & $269(81.0 \%)$ \\
\hline Female & $63(19.0 \%)$ \\
\hline \multicolumn{2}{|l|}{ Ethnicity } \\
\hline Han & $322(97.0 \%)$ \\
\hline Others & $10(3.0 \%)$ \\
\hline \multicolumn{2}{|l|}{ Education years $^{\mathrm{a}}$} \\
\hline$\leq 9$ & $259(79.2 \%)$ \\
\hline$>9$ & $68(20.8 \%)$ \\
\hline \multicolumn{2}{|l|}{ Living in rural areas } \\
\hline Yes & $243(73.2 \%)$ \\
\hline No & $89(26.8 \%)$ \\
\hline \multicolumn{2}{|l|}{ Ever been employed } \\
\hline Yes & $254(76.5 \%)$ \\
\hline No & $78(23.5 \%)$ \\
\hline \multicolumn{2}{|l|}{ Employment status } \\
\hline Employed & $69(20.8 \%)$ \\
\hline Unemployed & $263(79.2 \%)$ \\
\hline \multicolumn{2}{|l|}{ Marital status } \\
\hline Married & $121(36.4 \%)$ \\
\hline Others $^{c}$ & $211(63.6 \%)$ \\
\hline \multicolumn{2}{|l|}{ Living situation } \\
\hline Living with others & $263(79.2 \%)$ \\
\hline Living alone & $69(20.8 \%)$ \\
\hline \multicolumn{2}{|c|}{ Clinical characteristics } \\
\hline \multicolumn{2}{|c|}{ History of psychiatric treatment } \\
\hline Yes & $245(73.8 \%)$ \\
\hline No & $87(26.2 \%)$ \\
\hline \multicolumn{2}{|l|}{ Hospitalization } \\
\hline Yes & 183(55.1\%) \\
\hline No & $149(44.9 \%)$ \\
\hline \multicolumn{2}{|c|}{ IIIness duration(years $)^{b}$} \\
\hline$<5$ & $108(32.6 \%)$ \\
\hline$\geq 5$ & $223(67.4 \%)$ \\
\hline \multicolumn{2}{|c|}{ Medication at the time of violence } \\
\hline Yes & $69(20.8 \%)$ \\
\hline No & $263(79.2 \%)$ \\
\hline \multicolumn{2}{|c|}{ Alcohol at the time of violence } \\
\hline Yes & $41(12.3 \%)$ \\
\hline No & $291(87.7 \%)$ \\
\hline \multicolumn{2}{|l|}{ Drug users } \\
\hline Yes & $0(0.00 \%)$ \\
\hline No & $332(100.0 \%)$ \\
\hline \multicolumn{2}{|c|}{ Family history of mental illness } \\
\hline Yes & $29(8.7 \%)$ \\
\hline No & 303(91.3\%) \\
\hline
\end{tabular}

Table 1 (continued)

\begin{tabular}{|c|c|}
\hline & $n(\%)$ \\
\hline \multicolumn{2}{|c|}{ Criminological characteristics } \\
\hline \multicolumn{2}{|c|}{ History of criminal offense } \\
\hline Yes & $31(9.3 \%)$ \\
\hline No & $301(90.7 \%)$ \\
\hline \multicolumn{2}{|c|}{ Interpersonal violent types } \\
\hline Physical assault & $217(65.4 \%)$ \\
\hline Murder & $115(34.6 \%)$ \\
\hline \multicolumn{2}{|l|}{ The location of the crime } \\
\hline Co-residence & $77(23.2 \%)$ \\
\hline Residence of offender & $20(6.0 \%)$ \\
\hline Residence of victim & $56(16.9 \%)$ \\
\hline Public place & $173(52.1 \%)$ \\
\hline Remote place & $6(1.8 \%)$ \\
\hline \multicolumn{2}{|l|}{ The use of tools } \\
\hline Without tools & $54(16.3 \%)$ \\
\hline Bring own tools & $134(40.4 \%)$ \\
\hline Tools on-site & $144(43.4 \%)$ \\
\hline \multicolumn{2}{|l|}{ Number of attacks } \\
\hline Single & $51(15.4 \%)$ \\
\hline Repeated & $281(84.6 \%)$ \\
\hline \multicolumn{2}{|c|}{ The characteristics of victims } \\
\hline \multicolumn{2}{|l|}{ Sex } \\
\hline With female & $137(41.3 \%)$ \\
\hline Male & 195(58.7\%) \\
\hline \multicolumn{2}{|l|}{ Death } \\
\hline Yes & $119(35.8 \%)$ \\
\hline No & $213(64.2 \%)$ \\
\hline \multicolumn{2}{|l|}{${ }^{a}$ There were five missing data } \\
\hline \multicolumn{2}{|l|}{${ }^{\mathrm{b}}$ There was one missing data } \\
\hline ' Others: unmarried, divorce & \\
\hline
\end{tabular}

positive symptoms $(\mathrm{H}=9.604, p=0.008)$, negative symptoms $(\mathrm{H}=13.026, p=0.001)$, resistance $(\mathrm{H}=12.571$, $p=0.002)$, and the total score $(\mathrm{F}=7.386, p=0.001)$ among the three groups. Pairwise comparison after Bonferroni post hoc test found that the median scores of positive symptoms, negative symptoms, and resistance were significantly lower in the SV group than the other two groups $(p<0.05)$; there was no statistically significant difference in psychiatric symptom scores between the AV group and the RV group $(p>0.05)$ (Table 3$)$.

\section{Criminological characteristics}

There was a higher proportion (15.5\%) of offenders in the SV who had previous criminal history than that in the RV (5.2\%) and AV (9.1\%) ( $p=0.077)$. And there was a significant difference regarding the interpersonal violence location and types among the three groups $(p<0.001)$. 
Table 2 Comparison of demographic, clinical and criminological characteristics among groups

\begin{tabular}{|c|c|c|c|c|c|c|}
\hline & $\mathrm{RV} n=96$ & $\mathrm{AV} n=165$ & $\mathrm{SV} n=71$ & $F / x^{2}$ & $p$ & Post hoc analysis \\
\hline \multicolumn{7}{|c|}{ Demographic characteristics } \\
\hline Age [Mean (SD)] & $37.07(11.36)$ & $42.98(12.75)$ & $37.79(9.56)$ & 9.541 & $<0.001$ & $A V>S V=R V$ \\
\hline \multicolumn{7}{|l|}{ Sex } \\
\hline Male & $76(79.2 \%)$ & $131(79.4 \%)$ & $62(87.3 \%)$ & 2.333 & 0.311 & \\
\hline Female & $20(20.8 \%)$ & $34(20.6 \%)$ & $9(12.7 \%)$ & & & \\
\hline \multicolumn{7}{|l|}{ Ethnicity } \\
\hline Han & $93(96.9 \%)$ & 159(96.4\%) & $70(98.6 \%)$ & 0.689 & $0.839^{*}$ & \\
\hline Others & $3(3.1 \%)$ & $6(3.6 \%)$ & $1(1.4 \%)$ & & & \\
\hline \multicolumn{7}{|l|}{ Education years $^{a}$} \\
\hline$\leq 9$ & $76(80.9 \%)$ & $127(77.9 \%)$ & $56(79.2 \%)$ & 0.346 & 0.841 & \\
\hline$>9$ & 18(19.1\%) & $36(22.1 \%)$ & $14(20.0 \%)$ & & & \\
\hline \multicolumn{7}{|l|}{ Living in rural areas } \\
\hline Yes & $67(69.8 \%)$ & $130(78.8 \%)$ & $46(64.8 \%)$ & 5.754 & 0.056 & \\
\hline No & $29(30.2 \%)$ & $35(21.2 \%)$ & $25(35.2 \%)$ & & & \\
\hline \multicolumn{7}{|l|}{ Ever been employed } \\
\hline Yes & $72(75.0 \%)$ & $122(73.9 \%)$ & $60(84.5 \%)$ & 3.255 & 0.196 & \\
\hline No & $24(25.0 \%)$ & $43(26.1 \%)$ & $11(15.5 \%)$ & & & \\
\hline \multicolumn{7}{|l|}{ Employment status } \\
\hline Employed & $17(17.7 \%)$ & $28(17.0 \%)$ & $24(33.8 \%)$ & 9.319 & 0.009 & $S V>A V$ \\
\hline Unemployed & $79(82.3 \%)$ & $137(83.0 \%)$ & $47(66.2 \%)$ & & & \\
\hline \multicolumn{7}{|l|}{ Marital status } \\
\hline Married & $44(45.8 \%)$ & $57(34.5 \%)$ & $20(28.2 \%)$ & 6.010 & 0.050 & \\
\hline Others $^{c}$ & $52(54.2 \%)$ & $108(65.5 \%)$ & $51(71.8 \%)$ & & & \\
\hline \multicolumn{7}{|l|}{ Living situation } \\
\hline Living with others & $94(97.9 \%)$ & $119(72.1 \%)$ & $50(70.4 \%)$ & 28.771 & $<0.001$ & $\mathrm{RV}>\mathrm{AV}=\mathrm{SV}$ \\
\hline Living alone & $2(2.1 \%)$ & $46(27.9 \%)$ & $21(29.6 \%)$ & & & \\
\hline \multicolumn{7}{|c|}{ Clinical characteristics } \\
\hline \multicolumn{7}{|c|}{ History of psychiatric treatment } \\
\hline Yes & $78(81.2 \%)$ & $119(72.1 \%)$ & $48(67.6 \%)$ & 4.405 & 0.111 & \\
\hline No & 18(18.8\%) & $46(27.9 \%)$ & $23(32.4 \%)$ & & & \\
\hline \multicolumn{7}{|l|}{ Hospitalization } \\
\hline Yes & $57(59.4 \%)$ & $85(51.5 \%)$ & $41(57.7 \%)$ & 1.767 & 0.413 & \\
\hline No & $39(40.6 \%)$ & $80(48.5 \%)$ & $30(42.3 \%)$ & & & \\
\hline \multicolumn{7}{|c|}{ Illness duration(years) ${ }^{b}$} \\
\hline$<5$ & $32(33.3 \%)$ & $53(32.1 \%)$ & $23(32.9 \%)$ & 0.043 & 0.979 & \\
\hline$\geq 5$ & $64(66.7 \%)$ & $112(67.9 \%)$ & $47(67.1 \%)$ & & & \\
\hline \multicolumn{7}{|c|}{ Medication at the time of violence } \\
\hline Yes & $75(78.1 \%)$ & $136(82.4 \%)$ & $52(73.2 \%)$ & 2.641 & 0.267 & \\
\hline No & $21(21.9 \%)$ & $29(17.6 \%)$ & 19(26.8\%) & & & \\
\hline \multicolumn{7}{|c|}{ Alcohol at the time of violence } \\
\hline Yes & $7(7.3 \%)$ & $25(15.2 \%)$ & $9(12.7 \%)$ & 3.473 & 0.176 & \\
\hline No & $89(92.7 \%)$ & $140(84.8 \%)$ & $62(87.3 \%)$ & & & \\
\hline \multicolumn{7}{|c|}{ Family history of mental illness } \\
\hline Yes & $13(13.5 \%)$ & 10(6.1\%) & $6(8.5 \%)$ & 4.270 & 0.118 & \\
\hline No & $83(86.5 \%)$ & 155(93.9\%) & 65(91.5\%) & & & \\
\hline \multicolumn{7}{|c|}{ Criminological characteristics } \\
\hline \multicolumn{7}{|c|}{ History of criminal offense } \\
\hline Yes & $5(5.2 \%)$ & $15(9.1 \%)$ & $11(15.5 \%)$ & 5.123 & 0.077 & \\
\hline No & $91(94.8 \%)$ & 150(90.9\%) & $60(84.5 \%)$ & & & \\
\hline
\end{tabular}


Table 2 (continued)

\begin{tabular}{|c|c|c|c|c|c|c|}
\hline & $\mathrm{RV} n=96$ & $\mathrm{AV} n=165$ & $S V n=71$ & $F / x^{2}$ & $p$ & Post hoc analysis \\
\hline \multicolumn{7}{|c|}{ Interpersonal violent types } \\
\hline Murder & $63(65.6 \%)$ & $43(26.1 \%)$ & $9(12.7 \%)$ & 61.202 & $<0.001$ & $\mathrm{RV}>\mathrm{AV}=\mathrm{SV}$ \\
\hline Physical assault & $33(34.4 \%)$ & $122(73.9 \%)$ & $62(87.3 \%)$ & & & \\
\hline \multicolumn{7}{|c|}{ The location of the interpersonal violence } \\
\hline Co-residence & $70(72.9 \%)$ & $7(4.2 \%)$ & $0(0.0 \%)$ & 222.041 & $<0.001^{*}$ & $\mathrm{RV}>\mathrm{AV}=\mathrm{SV}$ \\
\hline Residence of offender & $2(2.1 \%)$ & $15(9.1 \%)$ & $3(4.2 \%)$ & & & - \\
\hline Residence of victim & $7(7.3 \%)$ & $48(29.1 \%)$ & $1(1.4 \%)$ & & & $A V>R V=S V$ \\
\hline Public place & $16(16.7 \%)$ & $94(57.0 \%)$ & 63(88.7\%) & & & $S V>A V>R V$ \\
\hline Remote place & $1(1.0 \%)$ & $1(0.6 \%)$ & $4(5.6 \%)$ & & & $S V>A V$ \\
\hline \multicolumn{7}{|l|}{ The use of tools } \\
\hline Without tools & $9(9.4 \%)$ & 23(13.9\%) & $22(31.0 \%)$ & 65.444 & $<0.001$ & $S V>A V=R V$ \\
\hline Bring own tools & $16(16.7 \%)$ & $81(49.1 \%)$ & $37(52.1 \%)$ & & & $S V=A V>R V$ \\
\hline Tools on-site & $71(74.0 \%)$ & $61(37.0 \%)$ & $12(16.9 \%)$ & & & $\mathrm{RV}>\mathrm{AV}>\mathrm{SV}$ \\
\hline \multicolumn{7}{|l|}{ Number of attacks } \\
\hline Single & $12(12.5 \%)$ & $24(14.5 \%)$ & $15(21.1 \%)$ & 2.504 & 0.286 & \\
\hline Repeated & $84(87.5 \%)$ & $141(85.5 \%)$ & $56(78.9 \%)$ & & & \\
\hline \multicolumn{7}{|c|}{ The characteristics of victims } \\
\hline \multicolumn{7}{|l|}{ Sex } \\
\hline With female & $57(59.4 \%)$ & $61(37.0 \%)$ & $19(26.8 \%)$ & 20.409 & $<0.001$ & $\mathrm{RV}>\mathrm{AV}=\mathrm{SV}$ \\
\hline Male & $39(40.6 \%)$ & $104(63.0 \%)$ & $52(73.2 \%)$ & & & \\
\hline \multicolumn{7}{|l|}{ Death } \\
\hline Yes & $64(66.7 \%)$ & $46(27.9 \%)$ & $9(12.7 \%)$ & 60.785 & $<0.001$ & $\mathrm{RV}>\mathrm{AV}>\mathrm{SV}$ \\
\hline No & $32(33.3 \%)$ & $119(72.1 \%)$ & $62(87.3 \%)$ & & & \\
\hline
\end{tabular}

Note: SD Standard Deviation, RV Relatives Victim group, AV Acquaintances Victim group, SV Stranger Victim group

* Fisher exact test

${ }^{a}$ There were two missing data in the RV and $\mathrm{AV}$, and one data missing in the SV

${ }^{\mathrm{b}}$ There was one missing data in the SV

'Others: unmarried, divorced, widowed

Table 3 Results of SDSS and BPRS

\begin{tabular}{|c|c|c|c|c|c|c|c|c|c|}
\hline & & \multicolumn{3}{|l|}{ Groups } & \multirow{2}{*}{\multicolumn{2}{|c|}{$\begin{array}{l}\text { ANOVA/ } \\
\text { Kruskal-Wallis } \\
\text { test }\end{array}$}} & \multicolumn{3}{|c|}{ Post hoc analysis } \\
\hline & & \multirow{2}{*}{$\begin{array}{l}\text { RV } \\
n=96\end{array}$} & \multirow{2}{*}{$\begin{array}{l}\text { AV } \\
n=165\end{array}$} & \multirow{2}{*}{$\begin{array}{l}\text { SV } \\
n=71\end{array}$} & & & \multirow{2}{*}{$\begin{array}{l}\text { RV-AV } \\
\Delta p\end{array}$} & \multirow{2}{*}{$\begin{array}{l}\text { RV-SV } \\
\Delta p\end{array}$} & \multirow{2}{*}{$\begin{array}{l}\text { AV-SV } \\
\Delta p\end{array}$} \\
\hline & & & & & $H / F$ & $p$ & & & \\
\hline SDSS & Median $(25 \%, 75 \%)$ & $8.00(6.00,11.00)$ & $8.00(5.50,11.00)$ & $7.00(3.00,11.00)$ & 4.075 & 0.130 & - & - & - \\
\hline Affect & Median (25\%,75\%) & $9.00(8.00,11.00)$ & $9.00(8.00,11.00)$ & $9.00(7.00,10.00)$ & 2.090 & 0.352 & - & - & - \\
\hline Positive & Median (25\%,75\%) & $12.00(10.00,15.00)$ & $13.00(10.00,15.50)$ & $10.00(8.00,14.00)$ & 9.604 & 0.008 & 1.000 & 0.026 & 0.010 \\
\hline Negative & Median (25\%,75\%) & $6.00(4.00,8.00)$ & $6.00(4.50,7.00)$ & $5.00(4.00,6.00)$ & 13.026 & 0.001 & 1.000 & 0.003 & 0.004 \\
\hline Activation & Median (25\%,75\%) & $5.00(4.00,6.75)$ & $5.00(4.00,6.00)$ & $5.00(4.00,6.00)$ & 0.457 & 0.796 & - & - & - \\
\hline Resistance & Median (25\%,75\%) & $10.00(8.25,11.00)$ & $10.00(8.00,12.00)$ & $8.00(6.00,11.00)$ & 12.571 & 0.002 & 1.000 & 0.006 & 0.003 \\
\hline BPRS-Total $^{a}$ & Mean (SD) & $45.68(9.481)$ & $44.74(9.302)$ & $40.38(9.232)$ & 7.386 & 0.001 & 1.000 & 0.001 & 0.003 \\
\hline
\end{tabular}

ane-way ANOVA

$\triangle p$ : adjusted $P$

$S D$ Standard Deviation

$R V$ Relatives Victim group, AV Acquaintances Victim group, VS Stranger Victim group 
Murders were more likely to occur among relatives (65.6\%), while physical assault in acquaintances (73.9\%) and strangers (87.3\%). Violence targeting relatives occurred more often in the co-residence of the perpetrator and the victim (72.9\%), while attacking acquaintances occurred more often in public places $(57.0 \%)$ and the victims' residence $(29.1 \%)$. Cases in which the victims were strangers occurred more often in public places (88.7\%). Regarding the gender of victims, $41.3 \%$ of cases involved female victims, and the difference among the RV (59.4\%), the AV (37.0\%), and SV (26.8\%) was statistically significant $(p<0.001)$. In terms of the severity, victims deceased in $35.8 \%$ of cases. The RV had the highest death rate of $66.7 \%$, followed by the AV (27.9\%), and the lowest was the SV $(12.7 \%)(p<0.001)$. Pairwise comparison after Bonferroni post hoc test also showed that the differences between the three groups were statistically significant. There were $83.7 \%$ of the offenders used tools, among which the RV used tools on-site in the highest proportion, accounting for $74.0 \%$, while the other two groups' patients brought their tools were $49.1 \%$ and $52.1 \%$, respectively, accounted for the highest percentage (Table 2). About specific victim relationships, in the RV, the parent $(32.3 \%)$ had the highest proportion, followed by the spouse (24.0\%); in the $\mathrm{AV}$, the neighbor (73.3\%) had the highest percentage. For the occurrence of death, the death risk of the RV was 13.78 times(95\% CI 6.081, $31.215, p<0.001)$ higher than that in the SV; when it comes to the $\mathrm{AV}$, the risk of death was 2.66 times $(95 \% \mathrm{CI}$ $1.224,5.795, p=0.014$ ) higher than that of the SV.

\section{Multinomial logistic regression analysis}

To assess the risk factors of different victim types, we used multinomial logistic regression to analyze the demographic characteristics and clinical characteristics analysis with $p<0.05$. The multinomial logistic regression analysis taking the AV group as a reference revealed that older patients had a lower possibility of attacking relatives, $\mathrm{OR}=0.966,95 \% \mathrm{CI}=0.9440 .990, p=0.005$, and strangers, $\mathrm{OR}=0.971,95 \% \mathrm{CI}=0.9440 .998, p=0.034$. This analysis also revealed that patients who lived with others were more likely to attack relatives, $\mathrm{OR}=15.057$, $95 \% \mathrm{CI}=3.508-64.628, p<0.001$, Furthermore, patients who were employed were more likely to attack strangers $\mathrm{OR}=2.034,95 \% \mathrm{CI}=1.036-3.994, p=0.039$. The regression equation did not include psychiatric symptoms (Table 4).

\section{Discussion}

In our study, the highest percentage of victims was acquaintances $(49.7 \%)$, followed by relatives (28.9\%) and strangers (21.4\%). The proportion of relatives was lower than that reported in two previous studies,
Table 4 Multinomial logistic regression

\begin{tabular}{lllll}
\hline group & factors & $\boldsymbol{p}$ & OR & $\mathbf{9 5 \% C l}$ \\
\hline RV & Age & $\mathbf{0 . 0 0 5}$ & 0.966 & $0.944-0.990$ \\
& Negative symptoms & 0.637 & 1.023 & $0.931-1.124$ \\
& Positive symptoms & 0.362 & 1.039 & $0.957-1.127$ \\
& Resistance & 0.853 & 0.988 & $0.868-1.124$ \\
Employed & 0.952 & 0.979 & $0.488-1.963$ \\
unemployed & Ref & & \\
Live with others & $<\mathbf{0 . 0 0 1}$ & 15.057 & $3.508-64.628$ \\
SV & Live alone & Ref & & \\
& Age & $\mathbf{0 . 0 3 4}$ & 0.971 & $0.944-0.998$ \\
& Negative symptoms & 0.081 & 0.885 & $0.772-1.015$ \\
& Positive symptoms & 0.490 & 0.965 & $0.873-1.067$ \\
& Resistance & 0.186 & 0.908 & $0.786-1.048$ \\
& Employed & $\mathbf{0 . 0 3 9}$ & 2.034 & $1.036-3.994$ \\
& Unemployed & Ref & & \\
Living with others & 0.576 & 0.822 & $0.413-1.635$ \\
& Living alone & Ref & & \\
\hline
\end{tabular}

Note: RV Relatives Victimization group, AV Acquaintances Victim group, VS Stranger Victim group, the reference group is AV

whereas the rate of relatives was $69.4 \%$ and $43.1 \%$, respectively $[15,16]$, while higher than that of a study in Sweden with 13\% [24], and comparable to Morgan with 33.3\% [25]. Different characteristic of offenders may result in the difference of victim targets. Some relatives of the schizophrenic patients may consider violence as an inevitable consequence of the disorder and tolerate the patient's violent behavior [34]. Generally, the victims would not report to the police unless being severely injured. However, the patient would usually be punished by law when committing violent acts against people outside the family. This may be one of the reasons why the data based on police records differ from the results of community surveys. In a Swedish study [24], only $13 \%$ of victims were relatives, while strangers made up 55.8\%. In our study, strangers accounted for only $21.4 \%$. This difference may also be from the study sample, in our study, we only focus on the original victim that was the first one being violently attacked. Police, security officers, and other people who were victimized in order to prevent the consequences of serious injuries were excluded, however, these kinds of victims were categorized as strangers in the aforementioned Swedish study [24].

In this study, the BPRS scores on positive symptoms, negative symptoms, and resistance symptoms of the offenders attacking strangers were lower than those attacking relatives and acquaintance. However, the multinomial regression analysis did not find significant contribution of these symptoms to the different types of 
victims, which suggesting that mental symptoms may not be the primary determinant of the type of victim.

A survey on schizophrenia patients who harm relatives and strangers found that insults, threats, and forced hospitalization were the primary inducement for the violence [35]. Patients who kill strangers are more likely to be homeless, exhibit anti-social behavior, and have fewer negative symptoms than those who kill family members [12].

Psychotic symptoms and violence have been associated for a long time, but the specific mechanism remains a mystery. Researchers have found that persecuted delusions can contribute to violent behavior in patients with schizophrenia [6], and delusions or hallucinations are related to violent behavior [36, 37]. However, studies have shown that delusions do not increase the patient's overall violence risk, although they may impact individual patients' violent behavior [38]. Delusional behavior does not typically lead to violent behavior [39], and rarely does the patient kills the victim by obeying the commanded auditory hallucination $[35,40]$. The occurrence of violent behavior may be a maladaptive resolution of conflict by the patient [41] or enhanced response to the stress in the stimulus situation [42]. The chances of people exhibiting aggressive behavior are higher when they feel scared [43].

Patients with schizophrenia frequently have concomitant cognitive impairment [1, 44]. Studies have shown that executive dysfunction is related to violent behavior $[45,46]$, because of the impairment of ability to adapt to the environment. It is sometimes complicated for individuals to adapt their behavior to environmental changes and to have inadequate inhibition, resulting in maladaptive challenges in social settings and more violent responses [46]. Unable to deal with conflicts reasonably, the presence of psychotic symptoms such as delusions and hallucinations may simply increase the probability of a patient experiencing conflict, however, whether violent behavior will eventually occur, is associated with the patient's executive function and other cognitive abilities to assess and implement a specific conflict processing strategy.

Taken together, symptoms, perpetrator-victim relationships, and circumstances may interact in complex ways to lead to violence. According to the Situation Action Theory (SAT) $[47,48]$, the act of crime results from a perception-choice process of persons' crime propensity and criminogenic exposure, and SAT maintains that acts of crime are best explained as moral actions. And a person's crime propensity was a consequence of their morality and ability to exercise self-control. The influence of a setting's moral context on action is always a question of its perceived moral context. A person's criminogenic exposure may be seen as his or her encounters with settings in which the (perceived) moral norms and their (perceived) levels of enforcement (or lack of enforcement) encourage reaches of rules of conduct (stated in law) in response to particular opportunities or frictions in their daily life [48]. Suffering from schizophrenia may influence the patients' morality and ability to exercise self-control and accurate perception of moral norms and enforcement in settings.

The multinomial regression analysis showed that employed and younger patients were more likely to attack strangers, and the younger patients living with others were more likely to attack relatives. The age, living situation, and employment may affect the living circumstances and the opportunity to connect with others. The stranger group of employed offenders can participate in more social life activities, and these activities reach out to more people than the other two groups, so it is more likely to contact strangers. Furthermore, they were less often co-live with others, lacking reasonable and adequate care and supervision. In the case of a patient confined at home, we assume a low risk of him or her harm a stranger.

The RV was more likely to live with others, and about $72.9 \%$ of the RV cases occurred at their co-residence, which suggests that most of the patients who attacked relatives were at home and had a small personal social circle, and the reason may be that they can only contact the relative who is caregivers at the most of the time.

The RV has a high proportion of cases involving female victims, which is consistent with previous studies showing that women account for most family victims [14, $15,24]$ because caregivers of the patients were mainly spouses or mothers. In a survey of schizophrenia patients with parricide, $98.1 \%$ lived with their parents [35]. Patients with schizophrenia may have some behavioral disorders due to the impact of the disease. Parents and other co-residents would ask them to do things such as not hanging out at night, not smoking at night, cleaning their room, regularly eating, taking medication, and saving [35]. The patient may perceive these restricted behaviors as parental intimidation and hostility toward them [49]. However, as the main caregiver, mothers play a significant role in compulsory drug feeding, forced hospitalization, and providing discipline. As a result, conflicts between caregivers and patients occurred, and patients would attack co-living people. Patients often inflict violence on their victims before their homicide occurred, with $40.7 \%$ of patients violently abusing their victims before the homicide occurred [35].Regarding the severity of victimization, the incidence of death in the relative group exceeded that of the other two groups significantly. Previous studies have also shown that patients with mental disorders inflict more severe injuries on their relatives [24]. A possible explanation would be the location of the 
incident, considering that most cases occurred in the coresidence. It was easier for the offender to obtain tools such as knives and sticks because the offender was familiar with the area, and the severity of the attack was more significant than if the offender had no tools. Outsiders cannot prevent violence and treat victims because of the relatively secretive environment of the incident, which increases the risk of death for the victim. Furthermore, since the study sample was drawn from physical assault and murder cases of schizophrenic patients identified by public security organs, some less severe injuries in the relative victims possibly were not included in the study sample.

People's movement patterns are determined by their individual routine activities and that people offend is related to their activity fields [48]. Frictions with their caregivers in daily life may also influence the patient's criminogenic exposure. In China, family members are primarily responsible for supervising patients with mental disorders [50, 51]. However, the majority of family members lack the knowledge and ability to coping violent crisis of mentally ill [51]. Many patients have recurrent symptoms due to inadequate or incorrect treatment $[52,53]$. As a result of residual symptoms [54], impaired cognitive and emotional function $[44,55]$, or stigma [56, 57], these patients repeatedly committed violent crimes. In this condition, the basic knowledge of mental disorders and violence prevention skills for family caregivers should be strengthened, which is crucial to disease rehabilitation and violence prevention. In the meanwhile, the community and government should make effort to construct a long-term sensible and reasonable management system for patients with mental disorders to improve their rehabilitation.

\section{Limitations}

There are some limitations need to be addressed in the current study. First, we only included cases from one forensic medicine assessment center in Sichuan province. Although this forensic center is responsible for most of the forensic psychiatric assessments for offenders with mental disorder in Sichuan Province (home to over 80 million people) [58], the findings may not be generalized to the entire country or other regions. However, the analytic methodology demonstrated in this study could be adopted for analysis in other regions. Second, due to the limitation of retrospective study, some information of the offenders such as the education level data were missing.

\section{Conclusion}

In the interpersonal violence cases committed by schizophrenia patients, the victim type correlates with demographic characteristics of offenders such as living situation, age, and employment status, but not with the psychiatric symptoms. Acquaintances and relatives are more likely to be injured by schizophrenic patients, Coresidents, caregivers and relatives were more vulnerable to suffer severe violence, especially the females.

It is essential to establish a guardianship system for patients with schizophrenia to improve caregiver awareness of the disease and risk management methods.

\section{Abbreviations \\ CCMD-3: The third edition of the Chinese Classification of Mental Disorder; RV: Relatives victim group; AV: Acquaintances victim group; VS: Stranger victim group; BPRS: The Brief Psychiatric Rating Scale; SDSS: The Social Disability Screening Schedule; SAT: Situation Action Theory.}

\section{Acknowledgements}

We are much thankful to those who supported this project.

\section{Authors' contributions}

$\mathrm{ZQH}, \mathrm{GQL}$ and YH conceived and designed the study, ZQH and GQL provided oversight and direction. $Y H, Y L$, and $M L Y$ contributed to data extracting. $Y H$ and $Y G$ contributed to data analysis and interpretation. YH drafted the manuscript. YH, ZQH, YG, MLY, and YL contributed to the revision of the manuscript. All authors have approved the final manuscript.

\section{Funding}

This work was supported by China Postdoctoral Science Foundation [grant number 2018M643488]; the National Natural Science Foundation of China [grant number 81901928].

\section{Availability of data and materials}

The data that support the findings of this study will be available from the corresponding author on reasonable request. The data are not publicly available due to the sensitivity of the subjects.

\section{Declarations}

\section{Ethics approval and consent to participate}

This study has been approved by the ethics committee board of Sichuan University (k2021001). Informed consent was waived by the ethics committee board of Sichuan University as this was no identifiable information in the database. All methods used in this study were carried out in accordance with relevant guidelines and regulations.

\section{Consent for publication}

Not applicable.

\section{Competing interests}

The authors declare that they have no competing interests.

Received: 4 September 2021 Accepted: 28 February 2022

Published online: 08 March 2022

\section{References}

1. Owen MJ, Sawa A, Mortensen PB. Schizophrenia. Lancet. 2016;388(10039):86-97.

2. Clement S, Foster N. Newspaper reporting on schizophrenia: A content analysis of five national newspapers at two time points. Schizophr Res. 2008;98(1-3):178-83.

3. Pescosolido BA, Manago B, Monahan J. Evolving public views on the likelihood of violence from people with mental illness: stigma and its consequences. Health Aff. 2019;38(10):1735-43.

4. Fazel S. Seena: schizophrenia, substance abuse, and violent crime. Jama. 2009;301(19):2016. 
5. Fleischman A, Werbeloff N, Yoffe R, Davidson M, Weiser M. Schizophrenia and violent crime: a population-based study. Psychol Med. 2014:44(14):3051-7.

6. Keers R, Ullrich S, DeStavola BL, Coid JW. Association of violence with emergence of persecutory delusions in untreated schizophrenia. Am J Psychiatry. 2014;171(3):332-9.

7. Brennan PA, Mednick SA, Hodgins S. Major mental disorders and criminal violence in a Danish birth cohort. Arch Gen Psychiatry. 2000:57(5):494-500

8. Lidz CW, Mulvey EP, Gardner W. The accuracy of predictions of violence to others. JAMA, J Am Med Assoc. 1993;269(8):1007-11.

9. Nielssen $\mathrm{OB}$, Westmore BD, Large MMB, Hayes RA. Homicide during psychotic illness in New South Wales between 1993 and 2002. Med J Aust. 2007;186(6):301-4.

10. Meehan J, Flynn S, Hunt IM, Robinson J, Bickley H, Parsons R, Amos T, Kapur N, Appleby L, Shaw J. Perpetrators of homicide with schizophrenia: A national clinical survey in England and Wales. Psychiatr Serv. 2006;57(11):1648-51.

11. Shaw J, Amos T, Hunt IM, Flynn S, Turnbull P, Kapur N, Appleby L. Mental illness in people who kill strangers: longitudinal study and national clinical survey. BMJ. 2004;328(7442):734-7.

12. Nielssen $O$, Bourget $D$, Laajasalo T, Liem M, Labelle A, Hakkanen-Nyholm $H$, Koenraadt F, Large MM. Homicide of Strangers by People with a Psychotic Illness. Schizophr Bull. 2011:37(3):572-9.

13. Matthias, Angermeyer C. Schizophrenia and violence. Acta Psychiatr Scand. 2010;102(Supplement s407):63-7.

14. Steadman HJ, Mulvey EP, Monahan J, Robbins PC, Appelbaum PS, Grisso T, Roth LH, Silver E. Violence by people discharged from acute psychiatric inpatient facilities and by others in the same neighborhoods. Arch Gen Psychiatry. 1998;55(5):393-401.

15. Estroff SE, Swanson JW, Lachicotte WS, Swartz M, Bolduc M. Risk reconsidered: targets of violence in the social networks of people with serious psychiatric disorders. Soc Psychiatry Psychiatr Epidemiol. 1998;33:S95-101.

16. Belli H, Ozcetin A, Ertem U, Tuyluoglu E, Namli M, Bayik YL, Simsek D. Perpetrators of homicide with schizophrenia: sociodemographic characteristics and clinical factors in the eastern region of Turkey. Compr Psychiatry. 2010;51(2):135-41.

17. Kageyama M, Solomon P, Yokoyama K. Psychological distress and violence towards parents of patients with schizophrenia. Arch Psychiatr Nurs. 2016;30(5):614-9.

18. Labrum T, Solomon PL. Rates of victimization of violence committed by relatives with psychiatric disorders. J Interpers Violence. 2017:32(19):2955-74.

19 Fazel S, Gulati G, Linsell L, Geddes JR, Grann M. Schizophrenia and Violence: Systematic Review and Meta-Analysis. Plos Med. 2009;6(8):e1000120

20. Schanda H, Knecht G, Schreinzer D, Stompe T, Ortwein-Swoboda G, Waldhoer T. Homicide and major mental disorders: a 25-year study. Acta Psychiatr Scand. 2004;110(2):98-107.

21 Baxter H, Duggan C, Larkin E, Cordess C, Page K. Mentally disordered parricide and stranger killers admitted to high-security care. 1: A descriptive comparison. J Forens Psychiatry. 2001;12(2):287-99.

22. Marleau JD, Millaud F, Auclair N. A comparison of parricide and attempted parricide: a study of 39 psychotic adults. Int J Law Psychiatry. 2003;26(3):269-79.

23. Chan B, Shehtman M. Clinical risk factors of acute severe or fatal violence among forensic mental health patients. Psychiatry Res. 2019;275:20-6.

24. Nordstrom A, Kullgren G. Victim relations and victim gender in violent crimes committed by offenders with schizophrenia. Soc Psychiatry Psychiatr Epidemiol. 2003;38(6):326-30.

25. Morgan VA, Morgan F, Valuri G, Ferrante A, Castle D, Jablensky A. A wholeof-population study of the prevalence and patterns of criminal offending in people with schizophrenia and other mental illness. Psychol Med. 2013;43(9):1869-80.

26. Chen Y-F. Chinese Classification of Mental Disorders (CCMD-3): Towards Integration in International Classification. Psychopathology. 2002;35(2-3):171-5

27. Lee S. Cultures in psychiatric nosology: The CCMD-2-R and International Classification of Mental Disorders. Cult Med Psychiatry. 1996:20(4):421
28. Hu J, Yang M, Huang $X$, Coid J. Forensic psychiatry in China. Int J Law Psychiatry. 2011;34(1):7-12.

29 Faustman WO, Overall JE. The brief psychiatric rating scale. Psychol Rep. 1962;10(3):799.

30 Overall JE, Hollister LE, Pichot P. Major psychiatric disorders - a 4-dimensional model. Arch Gen Psychiatry. 1967;16(2):146.

31. Shafer A. Meta-analysis of the brief psychiatric rating scale factor structure. Psychol Assess. 2005;17(3):324-35.

32 Li X-j, Wu J-h, Liu J-b, Li K-p, Fang W, Sun X-h, Ma S-h. The influence of marital status on the social dysfunction of schizophrenia patients in community. Int J Nurs Sci. 2015;2(2):149-52.

33. Cai GJ, Eaton WW. Mental disorders in China: Results of the national epidemiological survey in 12 areas - Cooper, JE, Sartorious, N. J Nerv Ment Dis. 1997;185(5):351-2.

34. Humphreys MS, Johnstone EC, Macmillan JF, Taylor PJ. Dangerous behaviour preceding first admissions for schizophrenia. Br J Psychiatry the J of Ment Sci. 1992;161(4):501

35. Ahn B-H, Kim J-H, Oh S, Choi SS, Ahn SH, Kim SB. Clinical features of parricide in patients with schizophrenia. Aust N Z J Psychiatry. 2012:46(7):621-9.

36. Ullrich S, Keers R, Shaw J, Doyle M, Coid JW. Acting on delusions: the role of negative affect in the pathway towards serious violence. J Forens Psychiatry Psychol. 2018;29(5):691-704.

37. Nordstrom A, Dahlgren L, Kullgren G. Victim relations and factors triggering homicides committed by offenders with schizophrenia. J Forens Psychiatry Psychol. 2006;17(2):192-203.

38. Appelbaum PS, Robbins PC, Monahan J. Violence and delusions: Data from the MacArthur Violence Risk Assessment Study. Am J Psychiatry. 2000;157(4):566-72

39 Wessely S, Buchanan A, Reed A, Cutting J, Everitt B, Garety P, Taylor PJ. Acting on delusions .1. prevalence. Br J Psychiatry. 1993;163:69.

40. Cheung P, Schweitzer I, Crowley K, Tuckwell V. Violence in schizophrenia: Role of hallucinations and delusions. Schizophr Res. 1997;26(2-3):181-90.

41. Weiss EM. Neuroimaging and neurocognitive correlates of aggression and violence in schizophrenia. Scientifica. 2012;2012:158646.

42. Sandi C, Haller J. Stress and the social brain: behavioural effects and neurobiological mechanisms. Nat Rev Neurosci. 2015;16(5):290-304.

43 Buchanan A, Reed A, Wessely S, Garety P, Taylor P, Grubin D, Dunn G. Acting on delusions .2. the phenomenological correlates of acting on delusions. Br J Psychiatry. 1993;163:77-81.

44. Green MF, Harvey PD. Cognition in schizophrenia: past, present, and future. Schizophr Res Cogn. 2014;1(1):e1-9.

45. Lamsma J, Cahn W, Fazel S, Genetic R. Outcome of Psychosis i: Cognition and violent behavior in psychotic disorders: A nationwide case-control study. Schizophr Res Cogn. 2020;19:100166.

46. Cruz AR, de Castro-Rodrigues A, Barbosa F. Executive dysfunction, violence and aggression. Aggress Violent Behav. 2020;51:7.

47. Wikstrom POH. Explaining crime and criminal careers: the DEA model of situational action theory. J Dev Life-Course Criminol. 2020;6(2):188-203.

48. Wikstrom POH, Ceccato V, Hardie B, Treiber K. Activity Fields and the Dynamics of Crime. J Quant Criminol. 2010;26(1):55-87.

49. Straznickas KA, McNiel DE, Binder RL. Violence toward family caregivers by mentally-ill relatives. Hosp Community Psychiatry. 1993:44(4):385-7.

50 Ran Mao-Sheng, Xiang Meng-Ze, Chan Cecilia, Lai-Wan Leff, Julian Simpson. Effectiveness of psychoeducational intervention for rural Chinese families experiencing schizophrenia: A randomised controlled trial. Soc Psychiatry Psychiatr Epidemiol. 2003;8(2):69-75.

51. Wang M, Jin G, Wei Y, Wang F, Pan Z, Chen L, Lu X. Awareness, utilization and influencing factors of social supports for main informal caregivers of schizophrenia patients: a cross-sectional study in primary care settings in Beijing, China. BMC Fam Pract. 2020;21(1):192.

52. Müller N. Mechanisms of Relapse Prevention in Schizophrenia. Pharmacopsychiatry. 2004;37(Suppl 2):S141-147.

53. Lam DH. Psychosocial family intervention in schizophrenia: a review of empirical studies. Psychol Med. 1991;21(2):423-41.

54. Durk W, Nienhuis FJ, Slooff CJ, Robert G. Natural course of schizophrenic disorders: a 15-year followup of a Dutch incidence cohort. Schizophr Bull. 1998;1:75-85

55. Bulgari V, Bava M, Gamba G, Bartoli F, Ornaghi A, Candini V, Ferla MT, Cricelli M, Bianconi G, Cavalera C, et al. Facial emotion recognition in people 
with schizophrenia and a history of violence: a mediation analysis. Eur Arch Psychiatry Clin Neurosci. 2020;270(6):761-9.

56. Delaney KR, Stigma Issues We Fail to See. Stigma Issues We Fail to See. Arch Psychiatr Nurs. 2012;26(4):333-5.

57. Lee S, Lee MTY, Chiu MYL, Kleinman A. Experience of social stigma by people with schizophrenia in Hong Kong. Br J Psychiatry. 2005;186:153-7.

58. Chen X, Zhang X, Wong SCP, Yang M, Kong D, Hu J. Characteristics of alleged homicide offenders with and without schizophrenia in Sichuan, China. Crim Behav Ment Health. 2018;28(2):202-15.

\section{Publisher's Note}

Springer Nature remains neutral with regard to jurisdictional claims in published maps and institutional affiliations.

- fast, convenient online submission

- thorough peer review by experienced researchers in your field

- rapid publication on acceptance

- support for research data, including large and complex data types

- gold Open Access which fosters wider collaboration and increased citations

- maximum visibility for your research: over $100 \mathrm{M}$ website views per year

At BMC, research is always in progress.

Learn more biomedcentral.com/submissions 